\title{
Transesophageal Echocardiography and Scopy Co-guided Percutaneous Mitral Balloon Valvuloplasty Procedure: Experience of a Tertiary Health Center with a Literature Review
}

\author{
Emre Ozdemir, Sadik Volkan Emren, Nihan Kahya Eren, Cem Nazli, Mehmet Tokaç \\ Department of Cardiology Clinic, Ataturk Education and Research Hospital, Izmir Katip Celebi University, Izmir, Turkey \\ ORCID: \\ Emre Ozdemir: https://orcid.org/0000-0003-0034-3022 \\ Sadik Volkan Emren: https://orcid.org/0000-0002-7652-1123 \\ Nihan Kahya Eren: https://orcid.org/0000-0002-0232-7694 \\ Cem Nazli: https://orcid.org/0000-0003-2231-3780 \\ Mehmet Tokaç: https://orcid.org/0000-0002-3223-7497
}

\section{Abstract}

Objective: Rheumatic valvular heart disease (RVHD) is an important health problem in Turkey, as in all developing countries. There is no exact prevalence data for RVHD in Turkey. But according to the Jones criteria, Turkey has a moderate risk for acute rheumatic fever (ARF). Patients with recurrent bouts of ARF resulting in carditis can progress to RVHD. The aim of this study was to evaluate percutaneous mitral balloon valvuloplasty (PMBV) procedures and compared the findings with the literature. Materials and Methods: PMBV procedure indication was determined according to the guidelines and heart team consensus. Echocardiography was evaluated prior to PBMV in all patients. The study included a total of 131 patients who underwent PMBV in the cardiology clinic of our hospital in the period 2007-2017. All PBMV procedures were performed under intraprocedural transesophageal echocardiography (TEE) guidance in addition to fluoroscopy with general anesthesia. Results: The patients comprised $83 \%$ female and $17 \%$ male with a mean age of $41.2 \pm 10.1$ years. Mean ejection fraction was $60.3 \% \pm 3.1 \%$, mean left atrium diameter was $46.7 \pm 5.3 \mathrm{~mm}$, and mean Wilkins score was $8.7 \pm 1$. After procedure with there was no mortality. There was statistically significant increase on mitral valve area and statistically significant decrease on pulmonary arterial pressure and statistically significant decrease on transmitral gradient. Conclusion: This is one of the few studies worldwide to have detected the safety and efficacy of PBMV with TEE and scopy coguidance. It is the first such study in Turkey. In accordance with the literature, the procedures performed with TEE and fluoroscopy co-guidance in our clinic have increased the safety of the procedure and decreased complication rates.

Keywords: Balloon valvuloplasty, echocardiography, fluoroscopy, mitral valve stenosis, rheumatic heart disease

\section{INTRODUCTION}

Rheumatic valvular heart disease (RVHD), which is a major cardiac health problem in Turkey, is also a common problem in developing countries. It is related to an exaggerated immune response due to cross-reactivity between Group-A beta-hemolytic streptococcus antigen and the valve tissue. ${ }^{[1]}$ There is no precise data on the prevalence of RVHD in Turkey. Patients with recurrent attacks of acute rheumatic fever (ARF)

Submission: 30-Jun-19 Revision: 25-Aug-19 Accepted: 05-Sep-19

Published Online: 25-Nov-19

\begin{tabular}{|l|l|}
\hline \multicolumn{3}{c|}{ Access this article online } \\
\hline Quick Response Code: & Website: \\
& \\
http://www.ijcva.com
\end{tabular}

resulting in carditis which can develop into RVHD. According to the Jones criteria, Turkey has a moderate risk for ARF in the general population. ${ }^{[1]}$ Severe mitral stenosis (MS) is the major cause of clinical worsening and limitation in the functional capacity of patients with RVHD. Since the first description

Address for correspondence: Dr. Emre Ozdemir, Department of Cardiology Clinic, Ataturk Education and Research Hospital, Izmir Katip Celebi University, Izmir, Turkey. E-mail: emreozdemir27@yahoo.com.tr

This is an open access journal, and articles are distributed under the terms of the Creative Commons Attribution-NonCommercial-ShareAlike 4.0 License, which allows others to remix, tweak, and build upon the work non-commercially, as long as appropriate credit is given and the new creations are licensed under the identical terms.

For reprints contact: reprints@medknow.com

How to cite this article: Ozdemir E, Emren SV, Eren NK, Nazli C, Tokaç M. Transesophageal echocardiography and scopy co-guided percutaneous mitral balloon valvuloplasty procedure: Experience of a tertiary health center with a literature review. Int J Cardiovasc Acad 2019;5:116-20. 
of the valvuloplasty procedure in 1984 , percutaneous mitral balloon valvuloplasty (PMBV) has been the primary procedural decision in many patients with MS. ${ }^{[2]}$ Although it entails mortal risks, which diminish with the increasing experience of the practitioner and the proper patient selection; PMBV is an effective method in the short and long term. ${ }^{[3]}$ To reduce complications in our clinic, the PMBV procedure is performed under transesophageal echocardiography (TEE) and general anesthesia. The aim of this study was to evaluate the PMBV procedures applied in our clinic between 2008 and 2017 and to compare the results with the literature.

\section{Materials and Methods}

Patients who underwent PMBV were retrospectively identified. The PMBV procedure indication was determined according to the guidelines ${ }^{[4]}$ and heart team (cardiologists, cardiac surgeons, and anesthetists) consensus. The demographic characteristics, before-after procedural echocardiography results, and rates of complications of the patients were retrospectively evaluated. Transthoracic echocardiography (TTE) was evaluated before the PBMV procedure in all patients. The echocardiographic parameters used were mitral valve area (echocardiographic mitral valve area was calculated using pressure half-time and the planimetric method, with the smallest value of these two accepted), transmitral gradients, Wilkins' Score, left atrial appendage, and mitral insufficiency severity. Patients with a Wilkins Score $\geq 11,>2^{\circ}$ mitral insufficiency and thrombus in the left atrium, were excluded from the study. The echocardiographic and clinical evaluations were performed at $24 \mathrm{~h}$ and at the end of the postprocedural $1^{\text {st }}$ month. A total of 131 patients were identified who underwent PMBV in the cardiology clinic of our hospital between 2007 and 2017. All procedures were applied after obtaining the patient's written and verbal consent. All PBMV procedures were performed under intraprocedural TEE guidance in addition to fluoroscopy with general anesthesia. Intraprocedural TEE was used as ultrasonographic guidance during the transseptal puncture (TSP) procedure by visualization of the tenting of the interatrial septum before pushing the needle for TSP [Figure 1]. All TSP procedures were performed with a Mullin sheath and Brockenbrough needle. After a successful TSP procedure, PMBV was performed with an Inoue balloon. The appropriate opening of the Inoue balloon can be monitored under TEE and if necessary, under fluoroscopy [Figure 2].

Intraprocedural TEE was also used to confirm the balloon position across from the mitral valve leaflets and to avoid damaging the subvalvular apparatus and for the early determination of postprocedural complications.

After the procedure, mitral regurgitation, valvular area, and transmitral gradient can be measured easily with TEE, so that mitral balloon valvuloplasty can be performed repeatedly during the same session if the result of the operation is suboptimal or insufficient [Figure 3].

TTE was performed at $24 \mathrm{~h}$ after the procedure before patients were discharged.

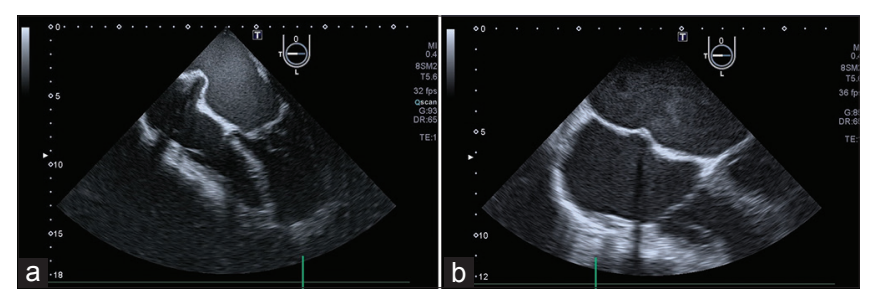

Figure 1: With the guidance of transesophageal echocardiography(TEE), transseptal puncture can be performed with confidence of detection of septal tenting on different degrees' view of TEE (a-b)
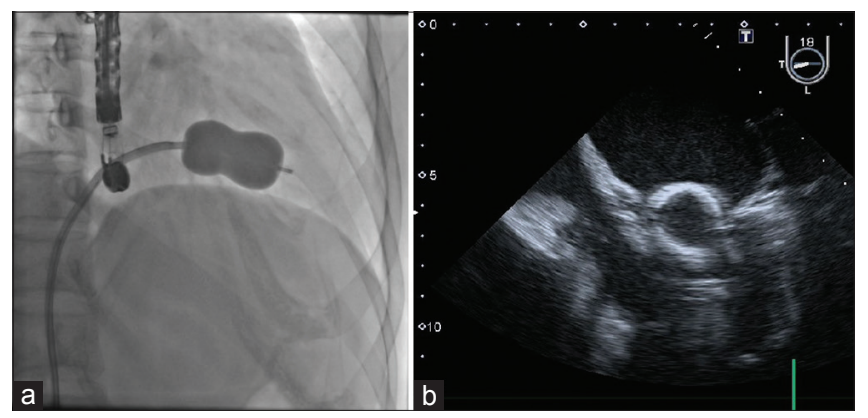

Figure 2: The appropriate opening of the Inoue balloon can be monitored under transesophageal echocardiography (a) and if necessary, under fluoroscopy (b)

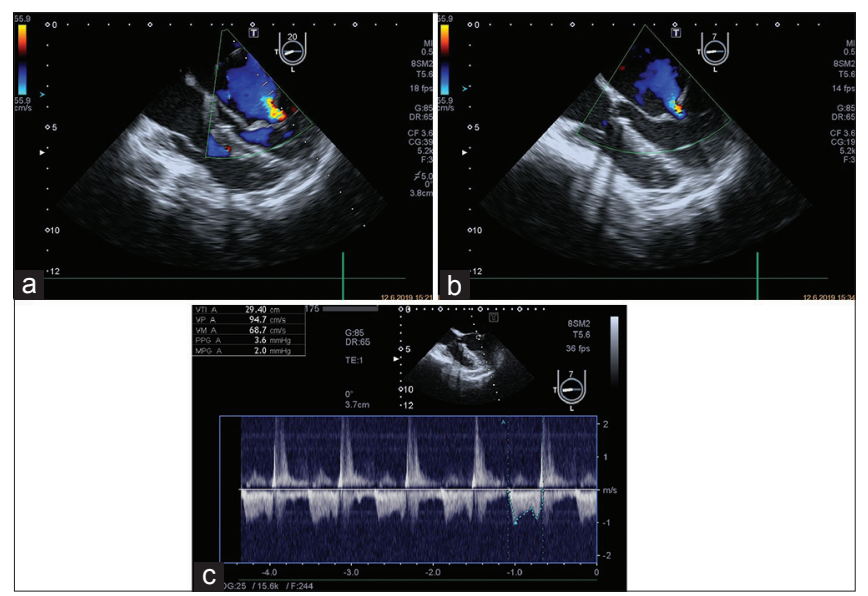

Figure 3: After the procedure, the mitral regurgitation (a-b), valvular area, and transmitral gradient (c) can be measured easily with transesophageal echocardiography, and if necessary procedure can repeat in same session

The postprocedural echocardiographic measurements in this study were accepted as the echocardiographic evaluation based on the 1-month findings.

Approval for this study was granted by the non-Interventional Clinical Research Ethics Committee of our hospital (decision no: 72, dated: 06.02.19).

\section{Statistical analysis}

Data obtained in the study were analyzed statistically using SPSS version 17 software (SPSS Inc., Chicago, IL, USA). Categorical variables were stated as a number of patients and percentage and continuous variables as mean \pm standard deviation values. Conformity of the data to normal distribution 
was assessed with visual (histogram and probability graphs) and analytical methods (Kolmogorov-Smirnov/Shapiro-Wilk test). Comparisons of categorical variables between groups were evaluated with the Chi-square test. Pre- and post-procedure values were compared using the paired-samples $t$-test. A value of $P<0.05$ was accepted as statistically significant.

\section{RESULTS}

The patients comprised $110(83 \%)$ females and $21(17 \%)$ males, with a mean age of $41.2 \pm 10.1$ years. Two patients were pregnant. The mean ejection fraction was $60.3 \%$ $\pm 3.1 \%$, mean left atrium diameter was $46.7 \pm 5.3 \mathrm{~mm}$. The mean Wilkins score was $8.7 \pm 1$ [Table 1]. The mitral valve area was measured as $1.12 \pm 0.19 \mathrm{~cm}^{2}$, before the procedure and $1.9 \pm 0.26 \mathrm{~cm}^{2}$ after the procedure $(P<$ 0.001) [Graph 1a and Table 2]. The mitral peak gradient was measured as $22.3 \pm 6.5 \mathrm{mmHg}$ before the procedure and $11.6 \pm 3.3 \mathrm{mmHg}$ after the procedure $(P<0.001)$ [Graph $1 \mathrm{~b}$ and Table 2]. The mean gradient was measured as $12.1 \pm 4.2 \mathrm{mmHg}$ before the procedure and $4.9 \pm 1.6 \mathrm{mmHg}$ after the procedure $(P<0.001)$ [Graph 2a and Table 2]. Mean systolic pulmonary arterial pressure was $42.4 \pm 15.2 \mathrm{mmHg}$ before the procedure and $26.9 \pm 8.1 \mathrm{mmHg}$ after the procedure $(P<0.001)$ [Graph $2 \mathrm{~b}$ and Table 2]. Severe mitral insufficiency was seen in 6 patients $(4.5 \%)$, three of which were due to chordae rupture and underwent urgent surgical mitral valve replacement (SMVR), and the other three were due to partial chordae rupture and were followed up medically. During the medical follow-up, one of these cases underwent elective SMVR. Cardiac tamponade was seen in one patient (1\%) [Table 3] and was treated with percutaneous pericardiocentesis, and the patient was discharged from the hospital after PBMV. Moderate mitral insufficiency was seen in 7 patients $(5.3 \%)$. The procedure was unsuccessful in $2(1.5 \%)$ patients with mitral valve area remaining $<1.5 \mathrm{~cm}^{2}$ after PMBV [Table 3] and those patients who underwent elective SMVR. No mortality occurred in any patient.

\section{Discussion}

Until the first description of PMBV by Inoue et al..$^{[2]}$ in 1984, the preferred treatment option for patients with severe MS was surgical mitral commissurotomy. After the Inoue technique was introduced, PBMV became an appropriate procedure for patients with MVA $<1.5 \mathrm{~cm}^{2}$, moderate-severe MS with symptoms NYHA class $\geq 2$, and for those with moderate-severe MS with new-onset atrial fibrillation and significant pulmonary hypertension (resting $>50 \mathrm{mmHg}$, with exercise $>60 \mathrm{mmHg}$ ). ${ }^{[4]}$ In 1990, the Wilkin score was described as a prediction of the success of PBMV in rheumatic mitral valve stenosis. The Wilkin score four components (1-leaflet mobility; 2-leaflet thickness; 3-subvalvular thickening; and 4-leaflet calcification) are individually scored from 1 to 4 points. ${ }^{[5]}$ If the score is $\leq 8$, then a favorable outcome is mostly predicted with PBMV. If the score is $>8$, with moderate-severe mitral insufficiency in the presence of an atrial thrombus, then SMVR is recommended.

Kronzon et al. ${ }^{[6]}$ reported the safety of TEE-guided PBMV, and Goldstein et al. ${ }^{[7]}$ used intraprocedural TEE for the PBMV procedure in 93 patients. Vilacosta et al. ${ }^{[8]}$ Ramondo et al. ${ }^{\left[{ }^{[9]}\right.}$ and Park et al. ${ }^{[10]}$ also reported shorter fluoroscopy time and procedure time with the use of intraprocedural TEE. As the current study was a retrospective cohort, fluoroscopy and procedure time could not be evaluated. However, as general anesthesia was used in the current study cases, procedure time was no shorter than that of the PMBV cases with fluoroscopy guidance only.

The National Heart, Lung, and Blood Institute classified complications related to mitral balloon valvuloplasty as important and unimportant. Important complications of the procedure are death, shock, the development of severe mitral insufficiency, systemic embolism, cardiac tamponade, urgent surgery requirement, and acute myocardium infarction. Unimportant complications include vasovagal reaction, arrhythmia requiring treatment, and iatrogenic atrium septum defect. The prevalence of all of these complications has been reported to be approximately $12 \%{ }^{[11]}$ The total complication rate of the current study was $5.3 \%$, which is lower than the above-reported values.

PMBV-related mortality has been shown to be $0 \%-3 \%$ in most studies, with causes of death reported as cardiac tamponade

\begin{tabular}{lc}
\hline $\begin{array}{l}\text { Table 1: General characteristics and basal } \\
\text { echocardiographic findings of patients }\end{array}$ \\
\hline Age (years) & $41.2 \pm 10.1$ \\
Gender, $n$ (\%) & \\
Female & $110(83)$ \\
Ejection fraction (\%) & $60.3 \pm 3.1$ \\
Left atrium (mm) & $46.7 \pm 5.3$ \\
Wilkins score & $8.7 \pm 1$ \\
\hline
\end{tabular}

Table 2: Echocardiographic changes before and after the procedure

\begin{tabular}{lccc}
\hline & $\begin{array}{c}\text { Before } \\
\text { procedure }\end{array}$ & $\begin{array}{c}\text { After } \\
\text { procedure }\end{array}$ & $\boldsymbol{P}$ \\
\hline MVA $\left(\mathrm{cm}^{2}\right)$ & $1.12 \pm 0.19$ & $1.9 \pm 0.26$ & $<0.001$ \\
Peak gradient $(\mathrm{mmHg})$ & $22.3 \pm 6.5$ & $11.6 \pm 3.3$ & $<0.001$ \\
Mean gradient $(\mathrm{mmHg})$ & $12.1 \pm 4.2$ & $4.9 \pm 1.6$ & $<0.001$ \\
SPAP $(\mathrm{mmHg})$ & $42.4 \pm 15.2$ & $26.9 \pm 8.1$ & $<0.001$ \\
\hline
\end{tabular}

MVA: Mitral valve area, SPAP: Systolic pulmonary arterial pressure

\begin{tabular}{|c|c|}
\hline Total complications, $n(\%)$ & $7(5.3)$ \\
\hline Severe mitral insufficiency, $n(\%)$ & $6(4.5)$ \\
\hline Cardiac tamponade, $n(\%)$ & $1(1)$ \\
\hline Moderate mitral insufficiency, $n(\%)$ & $7(5.3)$ \\
\hline Failed procedure, $n(\%)$ & $2(1.5)$ \\
\hline
\end{tabular}




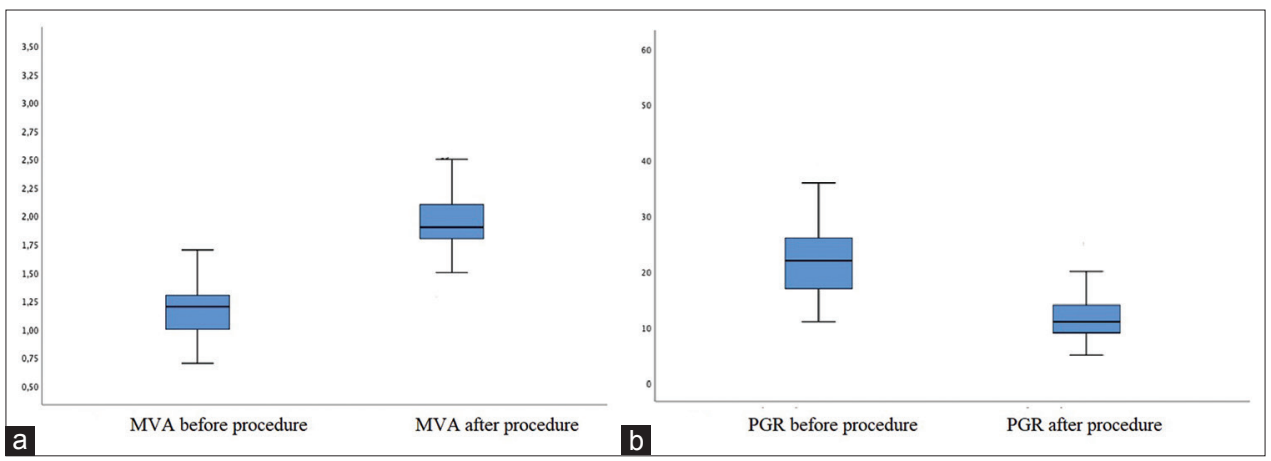

Graph 1: (a) Mitral valve area (MVA) distribution as $\mathrm{cm}^{2}$, and (b) peak transmitral gradient (PGR) distribution as mmHg before and after the percutaneous mitral balloon valvuloplasty procedure

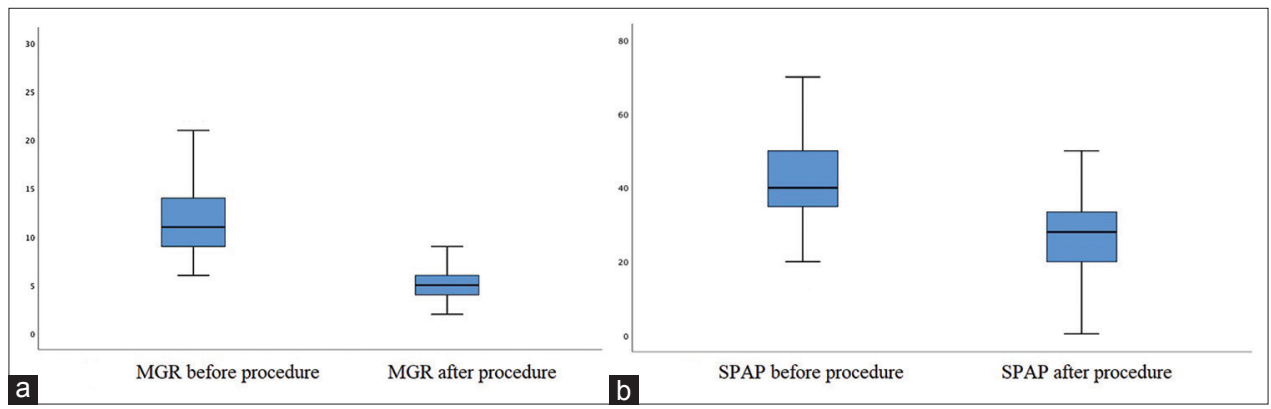

Graph 2: (a) Mean transmitral gradient (MGR) distribution as mmHg, and (b) systolic pulmonary arterial pressure (sPAP) distribution as mmHg before and after the percutaneous mitral balloon valvuloplasty procedure

and the development of severe mitral insufficiency. ${ }^{[12]}$ In the current study, no mortality occurred in any patient.

Hemopericardium, seen at the rate of $1 \%-3 \%$, is one of the most important causes of death and is often associated with TSP or myocardial injury. ${ }^{[12]}$ In the current study, cardiac tamponade occurred in 1 patient $(1 \%)$ and was treated with percutaneous pericardiocentesis.

Severe mitral regurgitation has been reported in 1.4\%-9.4\% of patients with $\mathrm{PMBV},{ }^{[13]}$ and $1.3 \%-3.2 \%$ of severe mitral insufficiency require urgent SMVR. ${ }^{[14]}$ In the current study, severe mitral insufficiency was seen in $4.5 \%$ of patients. Half of these cases $(n: 3)$ were due to chordae rupture and underwent urgent SMVR, while the other three were due to partial chordae rupture and they were followed up medically. During the medical follow-up, one of these patients underwent elective SMVR. Therefore, when compared with the findings in literature, the TEE and fluoroscopy co-guided PMBV procedures of the current study had low hemodynamically significant severe mitral insufficiency rates.

During TSP, TEE can visualize the position of the Mullins sheath and the Brockenbrough needle on the interatrial septum, and this makes the procedure safer. In the current study, with good procedural success rates, the mitral valve area increases, mitral peak gradient, mean gradient, and systolic pulmonary arterial pressure decreases were statistically significant with a value of $P<0.001$. Moreover, complication rates were lower (total complication rate of $5.3 \%$ ) and there was no mortality.

\section{Conclusion}

As our knowledge this study is one of the few studies from the worldwide and the first study from the Turkey, which have researched the safety and efficacy of PBMV with TEE and fluoroscopy co-guidance. Fluoroscopy and TEE-guided PMBV are safer with lower complication rates. However, this was a retrospective study, with some limitations regarding missing data such as fluoroscopy time.

\section{Financial support and sponsorship}

Nil.

\section{Conflicts of interest}

There are no conflicts of interest.

\section{RefERENCES}

1. Carapetis JR, McDonald M, Wilson NJ. Acute rheumatic fever. Lancet 2005;366:155-68.

2. Inoue $\mathrm{K}$, Owaki T, Nakamura T, Kitamura F, Miyamoto N. Clinical application of transvenous mitral commissurotomy by a new balloon catheter. J Thorac Cardiovasc Surg 1984;87:394-402.

3. Bouleti C, Iung B, Laouénan C, Himbert $\mathrm{D}$, Brochet $\mathrm{E}$, Messika-Zeitoun D, et al. Late results of percutaneous mitral commissurotomy up to 20 years: Development and validation of a risk score predicting late functional results from a series of 912 patients. Circulation 2012;125:2119-27.

4. Nishimura RA, Otto CM, Bonow RO, Carabello BA, Erwin JP $3^{\text {rd }}$, Guyton RA, et al. 2014 AHA/ACC guideline for the management of patients with valvular heart disease: Executive summary: A report of the American College of Cardiology/American Heart Association task force on practice guidelines. J Am Coll Cardiol 2014;63:2438-88. 
5. Wilkins GT, Weyman AE, Abascal VM, Block PC, Palacios IF. Percutaneous balloon dilatation of the mitral valve: An analysis of echocardiographic variables related to outcome and the mechanism of dilatation. Br Heart J 1988;60:299-308.

6. Kronzon I, Tunick PA, Schwinger ME, Slater J, Glassman E. Transesophageal echocardiography during percutaneous mitral valvuloplasty. J Am Soc Echocardiogr 1989;2:380-5.

7. Goldstein SA, Campbell A, Mintz GS, Pichard A, Leon M, Lindsay J Jr. Feasibility of on-line transesophageal echocardiography during balloon mitral valvulotomy: Experience with 93 patients. J Heart Valve Dis 1994;3:136-48.

8. Vilacosta I, Iturralde E, San Román JA, Gómez-Recio M, Romero C, Jiménez J, et al. Transesophageal echocardiographic monitoring of percutaneous mitral balloon valvulotomy. Am J Cardiol 1992;70:1040-4.

9. Ramondo A, Chirillo F, Dan M, Isabella G, Bonato R, Rampazzo C, et al. Value and limitations of transesophageal echocardiographic monitoring during percutaneous balloon mitral valvotomy. Int $\mathrm{J}$ Cardiol
1991;31:223-33.

10. Park SH, Kim MA, Hyon MS. The advantages of on-line transesophageal echocardiography guide during percutaneous balloon mitral valvuloplasty. J Am Soc Echocardiogr 2000;13:26-34.

11. Larry SD. Complications and mortality of percutaneous balloon mitral commissurotomy. A report from the national heart, lung, and blood institute balloon valvuloplasty registry. Circulation 1992;85:2014-24.

12. Harrison JK, Wilson JS, Hearne SE, Bashore TM. Complications related to percutaneous transvenous mitral commissurotomy. Cathet Cardiovasc Diagn 1994;Suppl 2:52-60.

13. Nobuyoshi M, Arita T, Shirai S, Hamasaki N, Yokoi H, Iwabuchi M, et al. Percutaneous balloon mitral valvuloplasty: A review. Circulation 2009;119:e211-9.

14. Nanjappa MC, Ananthakrishna R, Hemanna Setty SK, Bhat P, Shankarappa RK, Panneerselvam A, et al. Acute severe mitral regurgitation following balloon mitral valvotomy: Echocardiographic features, operative findings, and outcome in 50 surgical cases. Catheter Cardiovasc Interv 2013;81:603-8 